\title{
Editorial
}

\section{Molecular Electronics}

\author{
Linda A. Zotti ${ }^{1,2,3(1)}$
}

check for updates

Citation: Zotti, L.A. Molecular Electronics. Appl. Sci. 2021, 11, 4828. https://doi.org/10.3390/app11114828

Received: 18 May 2021

Accepted: 21 May 2021

Published: 25 May 2021

Publisher's Note: MDPI stays neutral with regard to jurisdictional claims in published maps and institutional affiliations.

Copyright: (C) 2021 by the author. Licensee MDPI, Basel, Switzerland. This article is an open access article distributed under the terms and conditions of the Creative Commons Attribution (CC BY) license (https:// creativecommons.org/licenses/by/ $4.0 /)$.
1 Departamento de Física Teórica de la Materia Condensada, Universidad Autónoma de Madrid, E-28049 Madrid, Spain; linda.zotti@uam.es

2 Condensed Matter Physics Center (IFIMAC), Universidad Autónoma de Madrid, E-28049 Madrid, Spain

3 Departamento de Física Aplicada I, Escuela Politécnica Superior, Universidad de Sevilla, E-41011 Seville, Spain

The field of molecular electronics is currently experiencing a renaissance. Recent advances in experimental techniques on the one hand, combined with theoretical modelling on the other, have enabled the exploration of new avenues, as well as allowing for significant progress along more traditional lines. The field is very diverse and embraces many cutting-edge research areas such as quantum interference, thermoelectrics, heat transfer, spintronics, switch devising, and biomolecular electronics. Studies on these subjects are driven by a multitude of needs in modern society: the current global quest for cheap and sustainable technology, the conversion of waste thermal energy, efficient ways of storing and processing information, and the fabrication of biocompatible and implantable devices to name but a few. Last but not least, molecules have proven to be an ideal platform for the advancement of knowledge of fundamental physics. This special issue aims at showcasing some of the many facets of research in molecular electronics and surveying the latest advances in the field. It contains seven studies, including five research papers [1-5] and two reviews [6,7], which span different areas of the field from both a theoretical and experimental perspective.

Funding: L.A.Z. thanks the University of Seville for their financial support through the VI PPIT-US program.

Acknowledgments: This publication was only possible with the invaluable contributions from the authors, reviewers, and the editorial team of Applied Sciences.

Conflicts of Interest: The author declares no conflict of interest.

\section{References}

1. Quintans, C.S.; Andrienko, D.; Domke, K.F.; Aravena, D.; Koo, S.; Díez-Pérez, I.; Aragonès, A.C. Tuning Single-Molecule Conductance by Controlled Electric Field-Inducedtransto-cisIsomerisation. Appl. Sci. 2021, 11, 3317. [CrossRef]

2. Romero-Muñiz, C.; Ortega, M.; Vilhena, J.G.; Pérez, R.; Cuevas, J.C.; Zotti, L.A. The Role of Metal Ions in the Electron Transport through Azurin-Based Junctions. Appl. Sci. 2021, 11, 3732. [CrossRef]

3. Koley, A.; Maiti, S.K.; Ojeda Silva, J.H.; Laroze, D. Spin Dependent Transport through Driven Magnetic System with Aubry-Andre-Harper Modulation. Appl. Sci. 2021, 11, 2309. [CrossRef]

4. Noori, M.D.; Sangtarash, S.; Sadeghi, H. The Effect of Anchor Group on the Phonon Thermal Conductance of Single Molecule Junctions. Appl. Sci. 2021, 11, 1066. [CrossRef]

5. Montes, E.; Vázquez, H. Role of the Binding Motifs in the Energy Level Alignment and Conductance of Amine-Gold Linked Molecular Junctions within DFT and DFT $+\sum$. Appl. Sci. 2021, 11, 802. [CrossRef]

6. Herrer, L.; Martín, S.; Cea, P. Nanofabrication Techniques in Large-Area Molecular Electronic Devices. Appl. Sci. 2020, 10, 6064. [CrossRef]

7. Dappe, Y.J. Attenuation Factors in Molecular Electronics: Some Theoretical Concepts. Appl. Sci. 2020, 10, 6162. [CrossRef] 